\title{
Dielectric properties of liquid systems: study of interactions in the systems carbon tetrachloride with benzene, toluene, and p-xylene
}

\author{
Adrián H. Buep*,1 \\ ${ }^{1}$ Facultad de Ciencias Exactas y Naturales, Facultad de Ingeniería y Facultad de Tecnología Informática, Universidad de \\ Belgrano-Villanueva 1324, C. P. 1426-Buenos Aires, Argentina \\ *Corresponding author e-mail address: adrian.buep@comunidad.ub.edu.ar
}

Published online: 19 December 2014; 23 July 2015 (version 2)

Cite as: Adrián H. Buep ScienceOpen Research 2015 (DOI: 10.14293/S2199-1006.1.SOR-PHYS.AVBRMV.v2)

Reviewing status: Please note that this article is under continuous review. For the current reviewing status and the latest referee's comments please click here or scan the QR code at the end of this article.

Primary discipline: Physics

Keywords: Excess dielectric properties, Binary mixtures, Excess functions, Permittivity of mixtures, Charge transfer complexes

\begin{abstract}
Intermolecular associations in liquid systems of non-polar and slightly polar compounds were studied through excess molar volumes $\left(V_{M}^{E}\right)$, and excess dielectric properties $\left(\varepsilon^{E}\right.$ and $\left.n_{D}^{2^{E}}\right)$ for mixtures of carbon tetrachloride $\left(\mathrm{CCl}_{4}\right)$ with benzene $\left(\mathrm{C}_{6} \mathrm{H}_{6}\right)$, toluene $\left(\mathrm{C}_{6} \mathrm{H}_{5} \mathrm{CH}_{3}\right)$, and p-xylene $\left(p-\left(\mathrm{CH}_{3}\right)_{2} \mathrm{C}_{6} \mathrm{H}_{4}\right)$. These excess properties were calculated from measurements of density $(\rho)$, static permittivity $(\varepsilon)$, and refractive index $\left(n_{D}\right)$ over the whole range of concentrations, at $298.15 \mathrm{~K}$. The values of the excess dielectric properties for these mixtures were fitted in two different ways, one through least squares using the Redlich-Kister equation and the other using a model developed to explain deviations from ideality. The first fit was found to be descriptive while the second gave the equilibrium constant values for the interaction products actually formed in the mixtures and the respective electronic polarizabilities and dipole moments, indicating the existence of interaction products.
\end{abstract}

\section{INTRODUCTION}

In previous work we studied the intermolecular associations in liquids through theoretical and experimental studies of the dielectric behavior of binary liquid mixtures [1-4]. In the present work on intermolecular associations in liquids we report measurements of permittivities, refractive indices, and densities for the $\mathrm{CCl}_{4}+\mathrm{C}_{6} \mathrm{H}_{6},+\mathrm{C}_{6} \mathrm{H}_{5} \mathrm{CH}_{3}$, and $+p-$ $\left(\mathrm{CH}_{3}\right)_{2} \mathrm{C}_{6} \mathrm{H}_{4}$ mixtures over the whole range of concentrations at $298.15 \mathrm{~K}$. These mixtures are of considerable interest because in them the departures from ideality stems not only from dispersion, dipolar, and inductive forces, but also from the specific interactions that lead to the formation of chargetransfer complexes between the vacant 3D level of the chlorine atom in $\mathrm{CCl}_{4}$ and the $\pi$ cloud of the aromatic hydrocarbons $[5,6]$. In particular the studies of the static permittivity of solutions, measured with high precision, has the advantage that the experimental values are very sensitive to the existence of different interaction products that may be formed in the mixtures [7].

The experimental values of density $(\rho)$, static permittivity $(\varepsilon)$, and refractive index for sodium light $\left(n_{D}\right)$ can be used to calculate the molar excess volume $\left(V_{M}^{E}\right)$, the excess static permittivity $\left(\varepsilon^{E}\right)$, and the excess permittivity at optical frequency $\left(n_{D}^{2^{E}}\right)$ over the whole range of concentrations. The excess values for the various mixtures can then be fitted using the Redlich-Kister [8] relation, however this was found to be insufficient, being only descriptive, therefore a model was developed to explain the excess dielectric considering all species present in the mixtures [3]. This previously developed model, based on the additivity of the electrical susceptibilities of the species present in a solution, required the formation of complexes $1: 1$ in the three systems studied to explain the departures from the ideality. However in the system $\mathrm{CCl}_{4}+$ $\mathrm{C}_{6} \mathrm{H}_{6}$ this did not seemed to be sufficient making it necessary consider the existence of another type of complex to explain the departure from the dielectric ideality. To perform the theoretical curve, the equilibrium constant values for the interaction products actually formed in the mixtures and the respective electronic polarizabilities and dipole moments can be randomly generated, in order to verify that the values obtained with this method are in concordance with those obtained from measurements of the enthalpy of mixing. It was expected that in this way the existence of other interaction product could be verified.

\section{EXPERIMENTAL SECTION Materials}

Reaction grade compounds were fractionally distilled twice and kept in dark bottles, under dry nitrogen. Benzene, toluene, and p-xylene were refluxed over metallic sodium. Purity was better than 99.9 mol\% through gas phase chromatography. In all distillations only the middle fraction coming over at the reported boiling point and comprising about 70\% was 
Table 1. Static Permittivities $(\varepsilon)$, refractive indices $\left(n_{D}\right)$, and densities $(\rho)$ for the pure liquids at $298.15 \mathrm{~K}$.

\begin{tabular}{|c|c|c|c|c|c|c|}
\hline Compound & $\varepsilon$ Exp. & $\varepsilon$ Lit. & $n_{D}$ Exp. & $n_{D}$ Lit. & $\rho\left(\mathrm{g} / \mathrm{cm}^{3}\right)$ Exp. & $\rho\left(\mathrm{g} / \mathrm{cm}^{3}\right)$ Lit. \\
\hline $\mathrm{CCl}_{4}$ & 2.2279 & $2.2276^{\mathrm{a}}$ & 1.45739 & $1.45734^{b}$ & 1.58436 & $1.58433^{b}$ \\
\hline $\mathrm{C}_{6} \mathrm{H}_{6}$ & 2.2727 & $2.2730^{\mathrm{a}}$ & 1.49769 & $1.49792^{c}$ & 0.87372 & $0.87370^{c}$ \\
\hline $\mathrm{C}_{6} \mathrm{H}_{5} \mathrm{CH}_{3}$ & 2.3757 & $2.3759^{d}$ & 1.49405 & $1.49404^{b}$ & 0.86224 & $0.86224^{b}$ \\
\hline$p-\left(\mathrm{CH}_{3}\right)_{2} \mathrm{C}_{6} \mathrm{H}_{4}$ & 2.2618 & $2.2612^{\mathrm{e}}$ & 1.49312 & $1.49314^{b}$ & 0.85673 & $0.85672^{b}$ \\
\hline
\end{tabular}

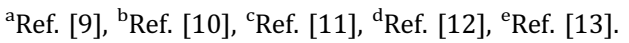

retained. Density, static permittivity, and refractive indices of the pure liquids at $298.15 \mathrm{~K}$ are shown in Table 1 together with literature values.

\section{Measurements}

Solutions were prepared by weighing amounts of the pure liquids by syringing them from into stoppered bottles to prevent evaporation and reduce possible error in mole fraction calculations. The mixtures were prepared on a Mettler balance with a $5 \times 0^{-5} \mathrm{~g}$ precision. The errors in mole fractions and in the volume fraction are estimated to be less than $1 \times 10^{-4}$ and less than $1 \times 10^{-4} \mathrm{ml} \mathrm{mol}^{-1}$, respectively. Temperature of all measurements was controlled to within $1 \times 10^{-2} \mathrm{~K}$. Densities were determined with a pycnometer [14] with an estimated error of less than $5 \times 10^{-5} \mathrm{~g} / \mathrm{cm}^{3}$. Before making determinations of densities, the pycnometer was calibrated with Millipore quality water. The static permittivity was determined as already described [12] employing the heterodyne beat method. The measurements were made at $100 \mathrm{kHz}$ with an error less then $2 \times 10^{-4}$ for all concentrations. The theoretical error calculated for the permittivity is $8 \times 10^{-5}$, however repeated determinations of identical samples gave an actual experimental error of $2 \times 10^{-4}$ units. This difference originates mainly in small differences in the filling of the cell. During all measurements the dielectric cell was thermostatted to $1 \times 10^{-2} \mathrm{~K}$ in a water bath for at least 30 min before experimental measurements. Refractive indices for sodium light were measured on an Abbe type Bausch \& Lomb precision refractometer with an error less than $5 \times 10^{-5}$. In order to keep a constant temperature, the measuring prism was water-jacketed using a temperature controlled bath with a temperature stability of $1 \times 10^{-2} \mathrm{~K}$.

The experimental data of the pure liquids and of the all the solutions were measured four times. The averaged results are listed in Table 2.

\section{RESULTS AND DISCUSSION}

The excess values were calculated from experimental measurements of permittivity, density, and refractive indices for the sodium D line by means of the following relations $[15,16]$ :

$$
n_{D}^{2^{E}}=n_{D}^{2}-\left(n_{D_{A}}^{2} \Phi_{A}^{0}+n_{D_{B}}^{2} \Phi_{B}^{0}\right)=n_{D}^{2}-n_{D}^{2^{I D}}
$$

Table 2. Static permittivities $(\varepsilon)$, refractive indices $\left(n_{D}\right)$, and densities $(\rho)$ for the three systems at $298.15 \mathrm{~K}$.

\begin{tabular}{|c|c|c|c|c|}
\hline$X$ & $\Phi$ & $\varepsilon$ & $n_{D}$ & $\rho\left(\mathrm{g} / \mathrm{cm}^{3}\right)$ \\
\hline \multicolumn{5}{|c|}{$X \mathrm{CCl}_{4}+(1-X) \mathrm{C}_{6} \mathrm{H}_{6}$} \\
\hline 0.0812 & 0.0876 & 2.2719 & 1.49452 & 0.93596 \\
\hline 0.1509 & 0.1618 & 2.2702 & 1.49169 & 0.98869 \\
\hline 0.2197 & 0.2342 & 2.2682 & 1.48894 & 1.04010 \\
\hline 0.2988 & 0.3164 & 2.2655 & 1.48582 & 1.09854 \\
\hline 0.3726 & 0.3921 & 2.2629 & 1.48283 & 1.15231 \\
\hline 0.4880 & 0.5086 & 2.2578 & 1.47819 & 1.23513 \\
\hline 0.5600 & 0.5802 & 2.2543 & 1.47540 & 1.28603 \\
\hline 0.6337 & 0.6526 & 2.2507 & 1.47230 & 1.33747 \\
\hline 0.7216 & 0.7379 & 2.2458 & 1.46879 & 1.39807 \\
\hline 0.8103 & 0.8227 & 2.2408 & 1.46522 & 1.45834 \\
\hline 0.8958 & 0.9032 & 2.2353 & 1.46163 & 1.51561 \\
\hline 0.9502 & 0.9540 & 2.2317 & 1.45945 & 1.55166 \\
\hline \multicolumn{5}{|c|}{$x_{C C l}+(1-X) C_{6} H_{5} C_{3}$} \\
\hline 0.0426 & 0.0389 & 2.3714 & 1.49295 & 0.89036 \\
\hline 0.1038 & 0.0952 & 2.3646 & 1.49126 & 0.93113 \\
\hline 0.1884 & 0.1742 & 2.3544 & 1.48879 & 0.98827 \\
\hline 0.2677 & 0.2493 & 2.3449 & 1.48624 & 1.04262 \\
\hline 0.3567 & 0.3350 & 2.3334 & 1.48349 & 1.10457 \\
\hline 0.4329 & 0.4095 & 2.3230 & 1.48091 & 1.15842 \\
\hline 0.5124 & 0.4884 & 2.3114 & 1.47799 & 1.21543 \\
\hline 0.6018 & 0.5786 & 2.2981 & 1.47460 & 1.28059 \\
\hline 0.6901 & 0.6692 & 2.2841 & 1.47111 & 1.34598 \\
\hline 0.7754 & 0.7583 & 2.2694 & 1.46762 & 1.41023 \\
\hline 0.8652 & 0.8536 & 2.2536 & 1.46371 & 1.47895 \\
\hline 0.9479 & 0.9430 & 2.2379 & 1.45983 & 1.54331 \\
\hline \multicolumn{5}{|c|}{$x_{C C l}+(1-X) p-\left(\mathrm{CH}_{3}\right)_{2} \mathrm{C}_{6} \mathrm{H}_{4}$} \\
\hline 0.0526 & 0.0417 & 2.2611 & 1.49187 & 0.88703 \\
\hline 0.1246 & 0.1003 & 2.2603 & 1.49012 & 0.92965 \\
\hline 0.2078 & 0.1705 & 2.2596 & 1.48783 & 0.98082 \\
\hline 0.2876 & 0.2403 & 2.2580 & 1.48559 & 1.03138 \\
\hline 0.3734 & 0.3183 & 2.2565 & 1.48302 & 1.08811 \\
\hline 0.4536 & 0.3941 & 2.2543 & 1.48046 & 1.14321 \\
\hline 0.5321 & 0.4712 & 2.2518 & 1.47780 & 1.19927 \\
\hline 0.6208 & 0.5619 & 2.2486 & 1.47453 & 1.26531 \\
\hline 0.7146 & 0.6624 & 2.2445 & 1.47083 & 1.33839 \\
\hline 0.7986 & 0.7565 & 2.2404 & 1.46716 & 1.40693 \\
\hline 0.8643 & 0.8331 & 2.2368 & 1.46418 & 1.46272 \\
\hline 0.9405 & 0.9253 & 2.2319 & 1.46048 & 1.52990 \\
\hline
\end{tabular}

$$
\begin{aligned}
V_{M}^{E} & =\frac{\left(M_{A} X_{A}^{0}+M_{B} X_{B}^{0}\right)}{\rho}-\frac{M_{A} X_{A}^{0}}{\rho_{A}}-\frac{M_{B} X_{B}^{0}}{\rho_{B}} \\
& =\frac{\left(M_{A} X_{A}^{0}+M_{B} X_{B}^{0}\right)}{\rho}-V_{M}^{\mathrm{E}^{I D}}
\end{aligned}
$$

wherein $M_{Z}, \Phi_{Z}^{0}$, and $X_{Z}^{0}(Z=A, B)$ are respectively molecular weight, ideal volume fraction, and molar fraction of the 
components. $\varepsilon^{I D}, n_{D}^{2^{I D}}$, and $V_{M}^{E^{I D}}$ correspond to the definition of ideal mixtures. Subscripts refer to the pure components A and $\mathrm{B}$.

The errors in $\varepsilon^{E}, n_{D}^{2^{E}}$, and $V_{M}^{E}$ for all concentrations are respectively less than $4 \times 10^{-4}, 3 \times 10^{-4}$, and $3 \times 10^{-3}$ $\mathrm{ml} / \mathrm{mol}$.

In Table 3 are shown the excess values calculated for the three mixtures with the Equations 1, 2 and 3.

Each set of results was fitted through least squares, with all points equally weighted, using the Redlich-Kister [8] equation:

$$
Y^{E}=C_{A}^{0}\left(1-C_{A}^{0}\right) \sum_{j=1}^{j=n} a_{j}\left(1-2 C_{A}^{0}\right)^{j-1}
$$

Table 3. Excess static permittivity $\left(\varepsilon^{E}\right)$, excess permittivity at optical frequency $\left(n_{D}^{2^{E}}\right)$, and excess molar volume $\left(V_{M}^{E}\right)$ for the three systems at $298.15 \mathrm{~K}$.

\begin{tabular}{|c|c|c|c|c|}
\hline$X$ & $\Phi$ & $\varepsilon^{E}$ & $n_{D}^{2^{E}}$ & $V_{M}^{E}(\mathrm{ml} / \mathrm{mol})$ \\
\hline \multicolumn{5}{|c|}{$X \mathrm{CCl}_{4}+(1-X) \mathrm{C}_{6} \mathrm{H}_{6}$} \\
\hline 0.0812 & 0.0876 & 0.0031 & 0.0010 & -0.001 \\
\hline 0.1509 & 0.1618 & 0.0048 & 0.0013 & -0.001 \\
\hline 0.2197 & 0.2342 & 0.0060 & 0.0018 & 0.002 \\
\hline 0.2988 & 0.3164 & 0.0070 & 0.0023 & -0.001 \\
\hline 0.3726 & 0.3921 & 0.0078 & 0.0024 & 0.002 \\
\hline 0.4880 & 0.5086 & 0.0079 & 0.0025 & 0.002 \\
\hline 0.5600 & 0.5802 & 0.0076 & 0.0028 & 0.000 \\
\hline 0.6337 & 0.6526 & 0.0072 & 0.0023 & 0.002 \\
\hline 0.7216 & 0.7379 & 0.0062 & 0.0022 & 0.000 \\
\hline 0.8103 & 0.8227 & 0.0050 & 0.0018 & -0.001 \\
\hline 0.8958 & 0.9032 & 0.0031 & 0.0009 & 0.000 \\
\hline 0.9502 & 0.9540 & 0.0017 & 0.0005 & -0.001 \\
\hline \multicolumn{5}{|c|}{$\mathrm{XCCl}_{4}+(1-\mathrm{X}) \mathrm{C}_{6} \mathrm{H}_{5} \mathrm{CH}_{3}$} \\
\hline 0.0426 & 0.0389 & 0.0015 & 0.0009 & -0.007 \\
\hline 0.1038 & 0.0952 & 0.0030 & 0.0020 & -0.016 \\
\hline 0.1884 & 0.1742 & 0.0045 & 0.0032 & -0.028 \\
\hline 0.2677 & 0.2493 & 0.0061 & 0.0037 & -0.034 \\
\hline 0.3567 & 0.3350 & 0.0072 & 0.0048 & -0.039 \\
\hline 0.4329 & 0.4095 & 0.0078 & 0.0052 & -0.041 \\
\hline 0.5124 & 0.4884 & 0.0079 & 0.0051 & -0.041 \\
\hline 0.6018 & 0.5786 & 0.0079 & 0.0049 & -0.042 \\
\hline 0.6901 & 0.6692 & 0.0073 & 0.0044 & -0.036 \\
\hline 0.7754 & 0.7583 & 0.0058 & 0.0038 & -0.031 \\
\hline 0.8652 & 0.8536 & 0.0041 & 0.0026 & -0.020 \\
\hline 0.9479 & 0.9430 & 0.0016 & 0.0010 & -0.009 \\
\hline \multicolumn{5}{|c|}{$X \mathrm{XCl}_{4}+(1-X) p-\left(\mathrm{CH}_{3}\right)_{2} \mathrm{C}_{6} \mathrm{H}_{4}$} \\
\hline 0.0526 & 0.0417 & 0.0007 & 0.0007 & 0.004 \\
\hline 0.1246 & 0.1003 & 0.0019 & 0.0016 & 0.010 \\
\hline 0.2078 & 0.1705 & 0.0036 & 0.0022 & 0.018 \\
\hline 0.2876 & 0.2403 & 0.0044 & 0.0029 & 0.021 \\
\hline 0.3734 & 0.3183 & 0.0055 & 0.0035 & 0.022 \\
\hline 0.4536 & 0.3941 & 0.0059 & 0.0039 & 0.026 \\
\hline 0.5321 & 0.4712 & 0.0060 & 0.0042 & 0.027 \\
\hline 0.6208 & 0.5619 & 0.0059 & 0.0041 & 0.024 \\
\hline 0.7146 & 0.6624 & 0.0052 & 0.0038 & 0.022 \\
\hline 0.7986 & 0.7565 & 0.0043 & 0.0029 & 0.018 \\
\hline 0.8643 & 0.8331 & 0.0032 & 0.0022 & 0.011 \\
\hline 0.9405 & 0.9253 & 0.0015 & 0.0011 & 0.006 \\
\hline
\end{tabular}

wherein $Y^{E}$ represents all excesses $\left(\varepsilon^{E}, n_{D}^{2^{E}}\right.$, and $\left.V_{M}^{E}\right)$, and $C_{A}^{0}$ represents mole fraction, $X_{A}^{0}$, or volume fraction, $\Phi_{A}^{0}$, for component A.

In each case, the number of coefficients, $a_{j}$, was established from an examination of the variation in standard deviation, $\sigma$, as given by:

$$
\sigma=\sqrt{\frac{\sum\left(Y_{E X P}^{E}-Y_{C A L C}^{E}\right)^{2}}{(n-m)}}
$$

where $n$ is the total number of data points and $m$ is the number of coefficients considered.

Coefficients, $a_{j}$, and standard deviations, $\sigma$, for the three systems are listed in Table 4.

Figures 1-4 show the experimental values of $\varepsilon^{E}, n_{D}^{2^{E}}$, and $V_{M}^{E}$ for the three systems as a function of molar concentrations, as well as the curves calculated with Equation 4.

Table 4. Coefficients, $a_{j}$, and standard deviations, $\sigma$, for the three

\begin{tabular}{|c|c|c|c|c|}
\hline$Y^{E}$ & $a_{1}$ & $a_{2}$ & $a_{3}$ & $\sigma$ \\
\hline \multicolumn{5}{|c|}{$X C C_{4}+(1-X) C_{6} H_{6}$} \\
\hline$\varepsilon^{E}$ & 0.03139 & -0.00102 & 0.00754 & 0.00010 \\
\hline$n_{D}^{2^{E}}$ & 0.01061 & & & 0.00015 \\
\hline$V_{M}^{E}$ & 0.0029 & & & 0.0013 \\
\hline \multicolumn{5}{|c|}{$X \mathrm{XCl}_{4}+(1-\mathrm{X}) \mathrm{C}_{6} \mathrm{H}_{5} \mathrm{CH}_{3}$} \\
\hline$\varepsilon^{E}$ & 0.03243 & & & 0.00019 \\
\hline$n_{D}^{2^{E}}$ & 0.02079 & & & 0.00017 \\
\hline$V_{M}^{E}$ & -0.1711 & & & 0.0010 \\
\hline \multicolumn{5}{|c|}{$X C C_{4}+(1-X) p-\left(\mathrm{CH}_{3}\right)_{2} \mathrm{C}_{6} \mathrm{H}_{4}$} \\
\hline$\varepsilon^{E}$ & 0.02404 & & & 0.00019 \\
\hline$n_{D}^{2^{E}}$ & 0.01646 & & & 0.00012 \\
\hline$V_{M}^{E}$ & 0.1023 & & & 0.0013 \\
\hline
\end{tabular}
systems at $298.15 \mathrm{~K}$.

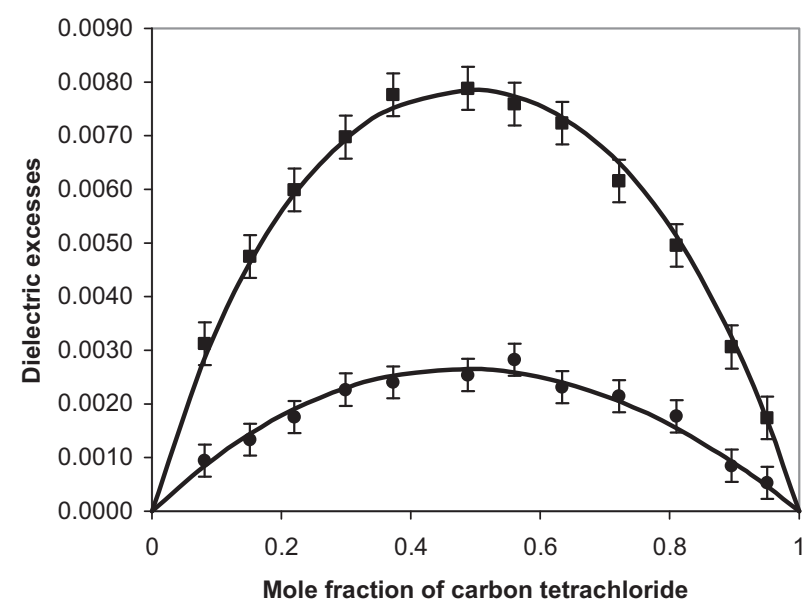

Figure 1. Dielectric excesses versus mole fraction $X$ for $\left[X_{C C l}+(1-X) C_{6} H_{6}\right]$ at $T=298.15 \quad \mathrm{~K} . \quad \varepsilon^{E}(\mathbf{\square}), \quad n_{D}^{2^{E}}(\bullet)$. The smoothed curves were calculated from Equation 4 with the parameters given in Table 4. Errors $\varepsilon^{E}: 4 \times 10^{-4} ; n_{D}^{2^{E}}: 3 \times 10^{-4}$. 


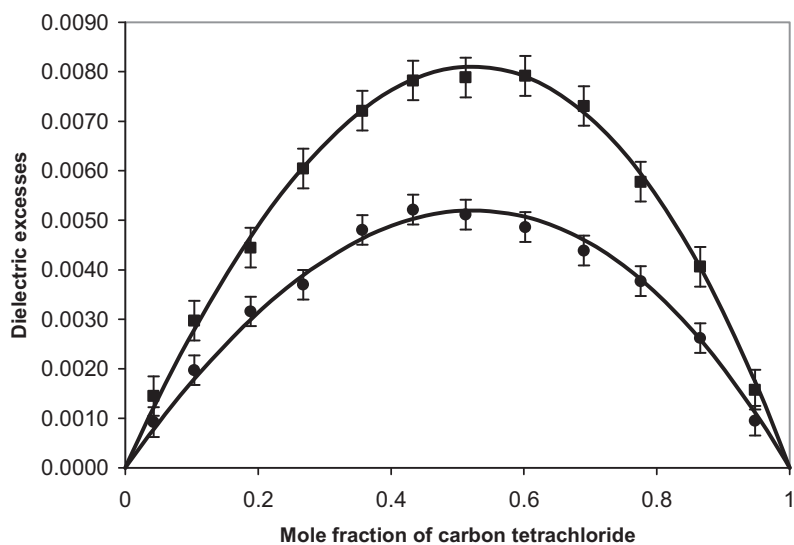

Figure 2. Dielectric excesses versus mole fraction $X$ for $\left[\mathrm{XCCl}_{4}+(1-X) \mathrm{C}_{6} \mathrm{H}_{5} \mathrm{CH}_{3}\right]$ at $T=298.15 \mathrm{~K} . \varepsilon^{E}(\boldsymbol{\square}), n_{D}^{2^{E}}(\bullet)$. The smoothed curves were calculated from Equation 4 with the parameters given in Table 4. Errors $\varepsilon^{E}: 4 \times 10^{-4} ; n_{D}^{2^{E}}: 3 \times 10^{-4}$.

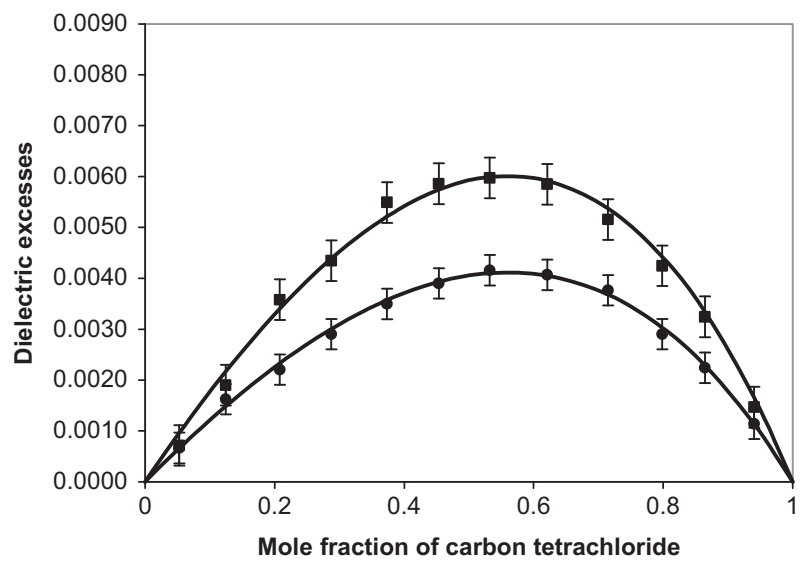

Figure 3. Dielectric excesses versus mole fraction $X$ for $\left[\mathrm{XCCl}_{4}+(1-X) p-\left(\mathrm{CH}_{3}\right)_{2} \mathrm{C}_{6} \mathrm{H}_{4}\right]$ at $T=298.15 \mathrm{~K} . \varepsilon^{E}(\mathbf{\square}), n_{D}^{2^{E}}(\bullet)$. The smoothed curves were calculated from Equation 4 with the parameters given in Table 4. Errors $\varepsilon^{E}: 4 \times 10^{-4} ; n_{D}^{2^{E}}: 3 \times 10^{-4}$.

Careful examination of the Figures 1-4 and Table 3 shows that the largest departures from ideality occur around equimolar concentrations, although there exists a slight asymmetry due to the difference in the size of the molecules. It can also be seen that $\varepsilon^{E}$ and $n_{D}^{2^{E}}$ are positive over the whole range of concentrations for the three systems. This is not the case with $V_{M}^{E}$, because it is slightly negative for $\mathrm{CCl}_{4}+\mathrm{C}_{6} \mathrm{H}_{5} \mathrm{CH}_{3}$, slightly positive for $\mathrm{CCl}_{4}+p-\left(\mathrm{CH}_{3}\right)_{2} \mathrm{C}_{6} \mathrm{H}_{4}$, and approximately null for $\mathrm{CCl}_{4}+\mathrm{C}_{6} \mathrm{H}_{6}$.

The magnitude of $\varepsilon^{E}$ for the solutions follow the sequence: $\mathrm{CCl}_{4}+\mathrm{C}_{6} \mathrm{H}_{5} \mathrm{CH}_{3} \approx \mathrm{CCl}_{4}+\mathrm{C}_{6} \mathrm{H}_{6}>\mathrm{CCl}_{4}+p-\left(\mathrm{CH}_{3}\right)_{2} \mathrm{C}_{6} \mathrm{H}_{4}$. The experimental data for $n_{D}^{2^{E}}$ follow the sequence: $\mathrm{CCl}_{4}+$ $\mathrm{C}_{6} \mathrm{H}_{5} \mathrm{CH}_{3}>\mathrm{CCl}_{4}+p-\left(\mathrm{CH}_{3}\right)_{2} \mathrm{C}_{6} \mathrm{H}_{4}>\mathrm{CCl}_{4}+\mathrm{C}_{6} \mathrm{H}_{6}$. The absolute values for $V_{M}^{E}$ are sequenced as: $\mathrm{CCl}_{4}+\mathrm{C}_{6} \mathrm{H}_{5} \mathrm{CH}_{3}>\mathrm{CCl}_{4}+$ $p-\left(\mathrm{CH}_{3}\right)_{2} \mathrm{C}_{6} \mathrm{H}_{4}>\mathrm{CCl}_{4}+\mathrm{C}_{6} \mathrm{H}_{6}$.

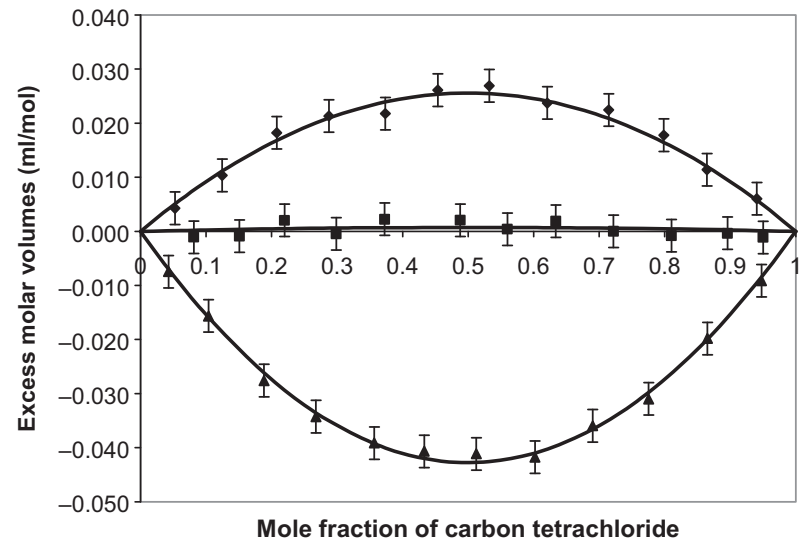

Figure 4. Excess molar volumes versus mole fraction $X$ for $\left[\mathrm{XCCl}_{4}+(1-\mathrm{X}) \mathrm{C}_{6} \mathrm{H}_{6}\right](\mathbf{\square}),\left[\mathrm{XCCl}_{4}+(1-\mathrm{X}) \mathrm{C}_{6} \mathrm{H}_{5} \mathrm{CH}_{3}\right](\mathbf{\Delta}),\left[\mathrm{XCCl}_{4}+\right.$ $\left.(1-X) p-\left(\mathrm{CH}_{3}\right)_{2} \mathrm{C}_{6} \mathrm{H}_{4}\right](\diamond)$. The smoothed curves were calculated from Equation 4 with the parameters given in Table 4. Errors $\varepsilon^{E}: 4 \times 10^{-4} ; n_{D}^{2^{E}}: 3 \times 10^{-4}$.

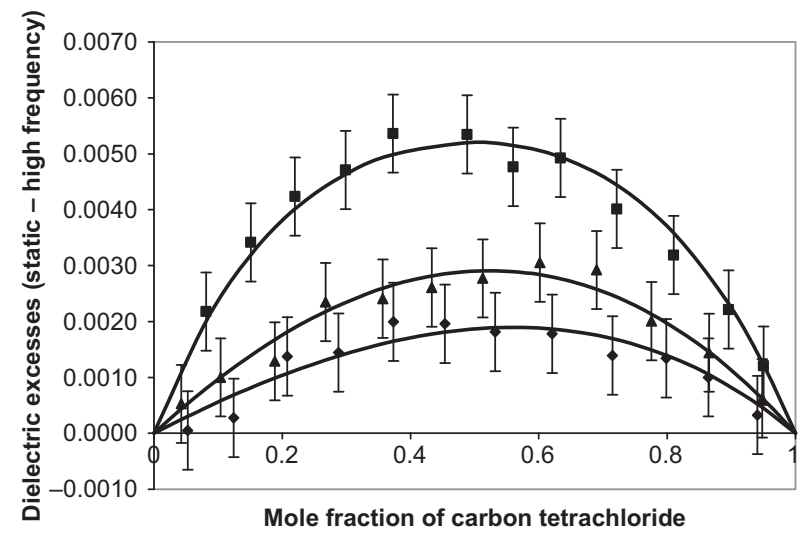

Figure 5. $\varepsilon^{E}-n_{D}^{2^{E}}$ versus mole fraction $X$ for $\left[X_{C C l}+(1-X) C_{6} H_{6}\right](\mathbf{\square}),\left[X C l_{4}+(1-X) C_{6} H_{5} C_{3}\right](\mathbf{\Delta}),\left[X C l_{4}+\right.$ $\left.(1-X) p-\left(\mathrm{CH}_{3}\right)_{2} \mathrm{C}_{6} \mathrm{H}_{4}\right](\diamond)$. The smoothed curves were calculated from Equation 4 with the parameters given in Table 4. Errors $\varepsilon^{E}-n_{D}^{2^{E}}: 7 \times 10^{-4}$.

Figure 5 shows the values of $\varepsilon^{E}-n_{D}^{2^{E}}$ for the three systems as a function of mole fraction of $\mathrm{CCl}_{4}$. There it can be seen that the differences follow the sequence: $\mathrm{CCl}_{4}+\mathrm{C}_{6} \mathrm{H}_{6}>\mathrm{CCl}_{4}+$ $\mathrm{C}_{6} \mathrm{H}_{5} \mathrm{CH}_{3}>\mathrm{CCl}_{4}+p-\left(\mathrm{CH}_{3}\right)_{2} \mathrm{C}_{6} \mathrm{H}_{4}$, indicating that the difference decreases with the increase in the number of $\mathrm{CH}_{3}$ groups on the aromatic ring. It is interesting to note at this point that an inverse sequence was found by Rosseinsky and Kellawi [17] when they plotted the association constant for complexes of $\mathrm{CCl}_{4}$ with benzene and methyl substituted benzene vs. number of $\mathrm{CH}_{3}$ substituents.

Evidence for the existence of electron-donor-acceptor interactions between $\mathrm{CCl}_{4}$ and the aromatic molecules can be found in the literature through values of enthalpies of mixing or melting points $[5,18,19]$. In dielectric data they can only be 
observed if high precision measurements are possible because the dielectric excesses in these mixtures are very small. As in this study the static permittivity measurements are of high precision, the interactions between $\mathrm{CCl}_{4}$ and the aromatic molecules could confirm the results found through measurements of enthalpies of mixing and melting points.

To confirm the existence of interactions we use a model that describes the permittivity of a mixture considering the multimers present and the electron-donor-acceptor complexes as separate entities [1, 3, 19]. In principle we can consider a mixture of two non-associated components $(A$ and $B$ ) which form a complex $A B$ in the solution. Then in the mixture there are, for every milliliter of solution, $N_{A}$ moles of monomers $A$, $N_{B}$ moles of monomers $B$ and $N_{A B}$ moles of the complex $A B$. Consequently the static permittivity and the high-frequency permittivity are expressed as:

$$
\begin{gathered}
\varepsilon=1+4 \pi N_{A V}\left[N_{A} \alpha_{A}^{E F}+N_{B} \alpha_{B}^{E F}+N_{A B} \alpha_{A B}^{E F}\right] \\
n_{D}^{2}=1+4 \pi N_{A V}\left[N_{A} \alpha_{A}^{E F e}+N_{B} \alpha_{B}^{E F e}+N_{A B} \alpha_{A B}^{E F e}\right]
\end{gathered}
$$

wherein $\alpha_{Z}^{E F}(Z=A, B, A B)$ is the effective polarizability of each species, $\alpha_{Z}^{E F e}$ is the effective electronic polarizability of each species and $N_{A V}$ is the Avogadro number.

Using the Onsager theory [20] the effective polarizabilities of all the species can be written as:

$$
\begin{gathered}
\alpha_{Z}^{E F}=\frac{\varepsilon \alpha_{Z}^{e}\left(n_{Z}^{2}+1\right)}{\left(2 \varepsilon+n_{Z}^{2}\right)}+\frac{\varepsilon\left(n_{Z}^{2}+2\right)^{2}(2 \varepsilon+1)}{3\left(2 \varepsilon+n_{Z}^{2}\right)^{2}} \frac{\mu_{Z}^{2}}{3 k T} \\
\alpha_{Z}^{E F e}=\frac{n_{D}^{2} \alpha_{Z}^{e}\left(n_{Z}^{2}+2\right)}{\left(2 n_{D}^{2}+n_{Z}^{2}\right)} \\
\alpha_{Z}^{e}=\frac{a_{Z}^{3}\left(n_{Z}^{2}-1\right)}{\left(n_{Z}^{2}+2\right)}
\end{gathered}
$$

wherein $a_{Z}, \mu_{Z}, k$, and Tare respectively the radius of the sphere that contains the species, the dipole moment of the species, the Boltzmann constant and the absolute temperature.

To calculate the radius $a_{Z}$ of the sphere containing species, the volume is assumed as the sum of the volumes of the molecules that constitute the species. Similarly the square refractive index of the species $\left(n_{Z}^{2}\right)$ is estimated as the sum of the squared refractive indices of the constituent monomers.

The number of moles of $A, B$, and $A B$ per unit volume are related by the following expressions:

$$
\begin{aligned}
& N_{A}^{0}=N_{A}+N_{A B} \\
& N_{B}^{0}=N_{B}+N_{A B}
\end{aligned}
$$

$$
\begin{aligned}
N & =N_{A}+N_{B}+N_{A B}=N_{A}^{0}-N_{A B}+N_{B}^{0}-N_{A B}+N_{A B} \\
& =N_{A}^{0}+N_{B}^{0}-N_{A B}=N^{0}-N_{A B}
\end{aligned}
$$

wherein $N_{A}^{0}$ and $N_{B}^{0}$ represent the number of moles per milliliter of components $A$ and $B$ in the final solution and $N$ represents the total number of moles of the species in the final homogeneous solution.

Dielectric excesses, $\varepsilon^{E}$ and $n_{D}^{2^{E}}$, can then be written as:

$$
\begin{aligned}
\varepsilon^{E}= & \varepsilon-\varepsilon^{I D}=1+4 \pi N_{A V}\left[N_{A} \alpha_{A}^{E F}+N_{B} \alpha_{B}^{E F}+N_{A B} \alpha_{A B}^{E F}\right] \\
& -\left(\varepsilon_{A} \Phi_{A}^{0}+\varepsilon_{B} \Phi_{B}^{0}\right) \\
n_{D}^{2^{E}}= & n_{D}^{2}-n_{D}^{2^{I D}}=1+4 \pi N_{A V}\left[N_{A} \alpha_{A}^{E F e}+N_{B} \alpha_{B}^{E F e}+N_{A B} \alpha_{A B}^{E F e}\right] \\
& -\left(n_{D_{A}}^{2} \Phi_{A}^{0}+n_{D_{B}}^{2} \Phi_{B}^{0}\right)
\end{aligned}
$$

wherein the effective polarizabilities $\alpha_{Z}^{E F}$ and $\alpha_{Z}^{E F e}$ ( $Z=A, B, A B$ ) are given by Equations (8) and (9).

In order to compare the experimental data with the values calculated using the proposed model the values of $N_{A}, N_{B}, N_{A B}$, $\alpha_{A B}^{e}$, and $\mu_{A B}$ are needed. The values of $N_{A}, N_{B}$, and $N_{A B}$ could be obtained using calorimetric data from equilibrium constant for complex formation [21]. There are two possible ways to calculate the number of species in the solution, the first is writing the equilibrium constant as a function of the number of moles of each species and the second in terms of the mole fractions of the species:

$$
\begin{gathered}
K_{A B}=\frac{N_{A B}}{N_{A} N_{B}}=\frac{N_{A B}}{\left(N_{A}^{0}-N_{A B}\right)\left(N_{A}^{0}-N_{A B}\right)} \\
K_{A B}^{X}=\frac{X_{A B}}{X_{A} X_{B}}
\end{gathered}
$$

The first association constant is expressed in $\mathrm{ml} / \mathrm{mol}$ and the second is dimensionless.

Both constants are related to each other as shown below:

$$
K_{A B}=\frac{N_{A B}}{N_{A} N_{B}}=\frac{N_{A B}}{N_{A} N_{B}} \frac{N^{2}}{N^{2}}=\frac{X_{A B}}{X_{A} X_{B}} \frac{1}{N}=\frac{K_{A B}^{X}}{N}
$$

where $X_{A}, X_{B}$, and $X_{A B}$ are the mole fractions of the species presents in the mixture defined as:

$$
X_{A}=\frac{N_{A}}{N} \quad X_{B}=\frac{N_{B}}{N} \quad X_{A B}=\frac{N_{A B}}{N}
$$

In this work to compute the excesses we follow the following procedure: first values of $K_{A B}^{X}$ and $\alpha_{A B}^{e}$ are generated randomly. When these values fit the excess permittivity at optical frequency $\left(n_{D}^{2^{E}}\right)$, within experimental error, random values of $\mu_{A B}$ are generated. Now the sum of the squares of the differences between the computed and the experimental values for both excesses are minimized. The fits are 
Table 5. Equilibrium constants, electronic polarizabilities, and dipole moments for the complexes.

\begin{tabular}{lccr}
\hline Complex & $\boldsymbol{K}_{\boldsymbol{A} \boldsymbol{B}}^{\boldsymbol{x}}$ & $\alpha_{A \boldsymbol{B}}^{e} \times \mathbf{1 0}^{\mathbf{2 3}}$ (ml) & $\boldsymbol{\mu}_{\boldsymbol{A B}}$ (Debye) \\
\hline $\mathrm{CCl}_{4}: \mathrm{C}_{6} \mathrm{H}_{6}$ & $0.199 \pm 0.005(0.215)$ & $2.135 \pm 0.002$ & $0.441 \pm 0.002$ \\
$\mathrm{CCl}_{4}: \mathrm{C}_{6} \mathrm{H}_{5} \mathrm{CH}_{3}$ & $0.377 \pm 0.002(0.413)$ & $2.330 \pm 0.001$ & $0.492 \pm 0.001$ \\
$\mathrm{CCl}_{4}: p-\left(\mathrm{CH}_{3}\right)_{2} \mathrm{C}_{6} \mathrm{H}_{4}$ & $0.558 \pm 0.002(0.556)$ & $2.515 \pm 0.001$ & $0.294 \pm 0.001$ \\
\hline
\end{tabular}

performed with an iterative method by solving the set of equations:

$$
\begin{gathered}
N_{A}=N_{A}^{0}-N_{A B} \\
N_{B}=N_{B}^{0}-N_{A B} \\
N=N_{A}^{0}+N_{B}^{0}-N_{A B} \\
n_{D}^{2}=1+4 \pi N_{A V}\left[N_{A} \alpha_{A}^{E F e}+N_{B} \alpha_{B}^{E F e}+N_{A B} \alpha_{A B}^{E F e}\right] \\
N_{A B}=\frac{K_{A B}^{X} N_{A} N_{B}}{N} \\
\alpha_{B}^{E F}=\frac{\varepsilon \alpha_{B}^{e}\left(n_{B}^{2}+1\right)}{\left(2 \varepsilon+n_{B}^{2}\right)}+\frac{\varepsilon\left(n_{B}^{2}+2\right)^{2}(2 \varepsilon+1)}{3\left(2 \varepsilon+n_{B}^{2}\right)^{2}} \frac{\mu_{B}^{2}}{3 k T} \\
\alpha_{A B}^{E F}=\frac{\varepsilon \alpha_{A B}^{e}\left(n_{A B}^{2}+1\right)}{\left(2 \varepsilon+n_{A B}^{2}\right)}+\frac{\alpha_{A}^{E F e}}{3 \pi N_{A V}\left[N_{A} \alpha_{A}^{E F}+N_{B} \alpha_{B}^{E F}+N_{A B} \alpha_{A B}^{E F}\right]} \\
3\left(2 \varepsilon+n_{A B}^{2}\right)^{2} \\
\alpha_{A}^{E F}=\frac{\varepsilon \alpha_{A}^{e}\left(n_{A}^{2}+1\right)}{\left(2 \varepsilon+n_{A}^{2}\right)}+\frac{\left.\alpha_{D}^{2}+n_{B}^{2}\right)}{3 k T} \\
\alpha_{A B}^{E F e}=\frac{n_{D}^{2} \alpha_{A B}^{e}\left(n_{A B}^{2}+2\right)}{\left(2 n_{D}^{2}+n_{A B}^{2}\right)}
\end{gathered}
$$

wherein the initial value of $N_{A B}$ is zero and the dipole moments of toluene and p-xylene are taken equal to $0.351 D$ and $0.148 D$ respectively.

To perform the theoretical curve, in each mixture over $10^{6}$ random values for $K_{A B}^{X}$ and $\alpha_{A B}^{e}$ were generated. For each pair of values that fit the dielectric excess at high frequency, random values for $\mu_{A B}$ are generated until the dielectric excess at low frequency is fitted or a maximum of $10^{3}$ generated values are reached. When this step is completed the process returns to the starting point and starts the fit again. For each mixture 5 total fits were made, therefore 5 values for $K_{A B}^{X}, \alpha_{A B}^{e}$, and $\mu_{A B}$ were obtained. In Table 5 , mean values and the corresponding errors are shown. The error is determined using the values of the parameters obtained in each of the 5 total fits. The error shown in Table 5 was calculated as half of the difference between the maximum value and the minimum value taken by each of the three parameters.

The values in parenthesis in the second column were obtained from measurements of the enthalpy of mixing [21] and show reasonable agreement with those obtained in this work. In the system $\mathrm{CCl}_{4}+\mathrm{C}_{6} \mathrm{H}_{6}$ the excess dielectric points at low frequency cannot be fitted by the model considering only a 1:1 complex. In the other two systems the experimental data and the model agree in the whole concentration range. It should be clarified here that if the 1:1 complex is not considered, in the three mixtures, the model gives values of static permittivity and high-frequency permittivity that are similar to those of the ideal mixture and therefore the excesses are zero.

Experimental values and the curve generated with the model are shown in Figures 6-8 using the parameters given in Table 5 .

As mentioned above, in the system $\mathrm{CCl}_{4}+\mathrm{C}_{6} \mathrm{H}_{6}$ the dielectric excesses at low frequency cannot be fitted in the $\mathrm{CCl}_{4}$ low concentration if only a 1:1 complex is considered. Figure 6 shows that at low concentration in $\mathrm{CCl}_{4}$ the experimental data show values higher than those calculated with the model. This could be because in addition to the $\mathrm{CCl}_{4}: \mathrm{C}_{6} \mathrm{H}_{6}$ complex there exists a $\mathrm{CCl}_{4}: 2 \mathrm{C}_{6} \mathrm{H}_{6}$ complex that increases the excess value in the range of concentrations where this species is important. Then, to explain the departure from the ideality in this system, we can consider a mixture of two non-associated components ( $A$ and $B$ ) forming the $A B$ and $A 2 B$ complexes in the solution. Then in the mixture there are for every milliliter of solution: $N_{A}$ moles of monomers $A, N_{B}$ moles of monomers $B, N_{A B}$ moles of the complex $A B$ and $N_{A 2 B}$ moles of the complex $A 2 B$. In this case, the static permittivity and the high-frequency permittivity are expressed as:

$$
\varepsilon=1+4 \pi N_{A V}\left[N_{A} \alpha_{A}^{E F}+N_{B} \alpha_{B}^{E F}+N_{A B} \alpha_{A B}^{E F}+N_{A 2 B} \alpha_{A 2 B}^{E F}\right]
$$




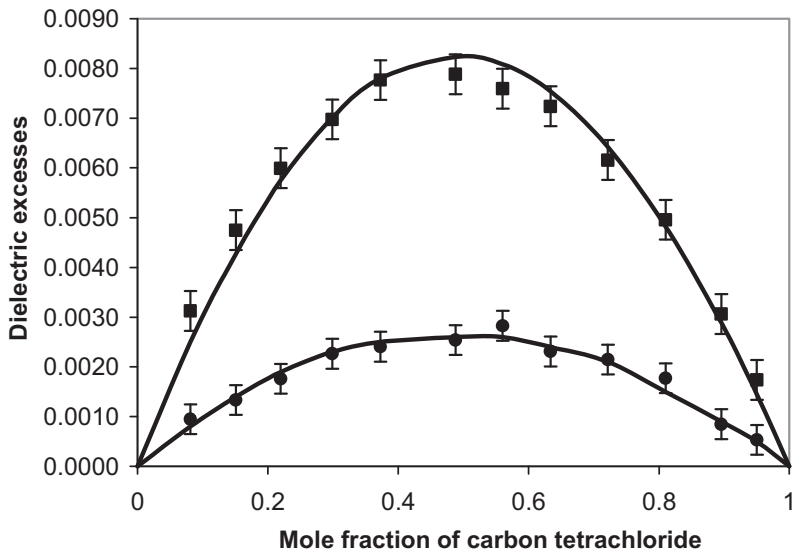

Figure 6. Dielectric excesses versus mole fraction $X$ for $\left[X_{C C l}+(1-X) C_{6} H_{6}\right] . \varepsilon^{E}(\square), n_{D}^{2^{E}}(\bullet)$. The smoothed curves were calculated from the model considering a $\mathrm{CCl}_{4}: \mathrm{C}_{6} \mathrm{H}_{6}$ complex with the parameters given in Table 5. Errors $\varepsilon^{E}: 4 \times 10^{-4} ; n_{D}^{2^{E}}$ : $3 \times 10^{-4}$.

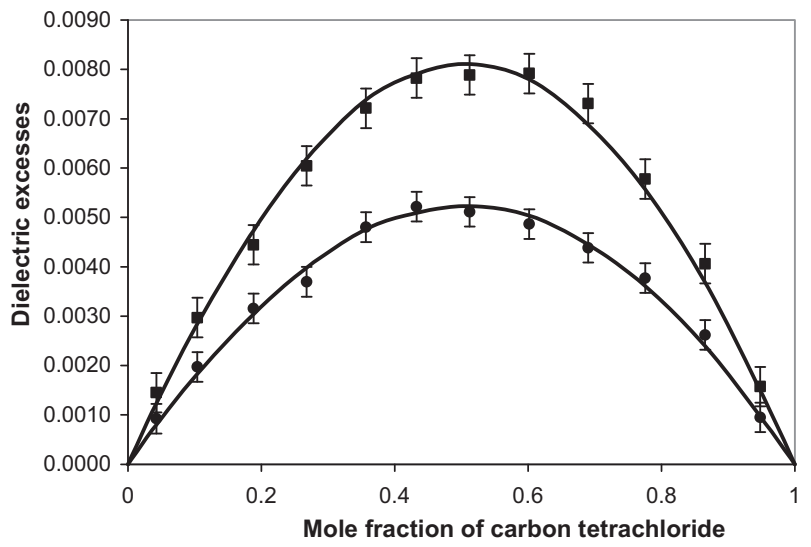

Figure 7. Dielectric excesses versus mole fraction $X$ for $\left[\mathrm{XCCl}_{4}+(1-X) \mathrm{C}_{6} \mathrm{H}_{5} \mathrm{CH}_{3}\right] . \varepsilon^{E}(\boldsymbol{\square}), n_{D}^{2^{E}}(\bullet)$. The smoothed curves were calculated from the model considering a $\mathrm{CCl}_{4}: \mathrm{C}_{6} \mathrm{H}_{5} \mathrm{CH}_{3}$ complex with the parameters given in Table 5. Errors $\varepsilon^{E}: 4 \times$ $10^{-4} ; n_{D}^{2^{E}}: 3 \times 10^{-4}$.

$$
n_{D}^{2}=1+4 \pi N_{A V}\left[N_{A} \alpha_{A}^{E F e}+N_{B} \alpha_{B}^{E F e}+N_{A B} \alpha_{A B}^{E F e}+N_{A 2 B} \alpha_{A 2 B}^{E F e}\right]
$$

The amounts of monomers and complexes in the final solution are related by the following expressions:

$$
\begin{gathered}
N_{A}^{0}=N_{A}+N_{A B}+N_{A 2 B} \\
N_{B}^{0}=N_{B}+N_{A B}+2 N_{A 2 B} \\
N=N_{A}+N_{B}+N_{A B}+N_{A 2 B}=N^{0}-N_{A B}-2 N_{A 2 B}
\end{gathered}
$$

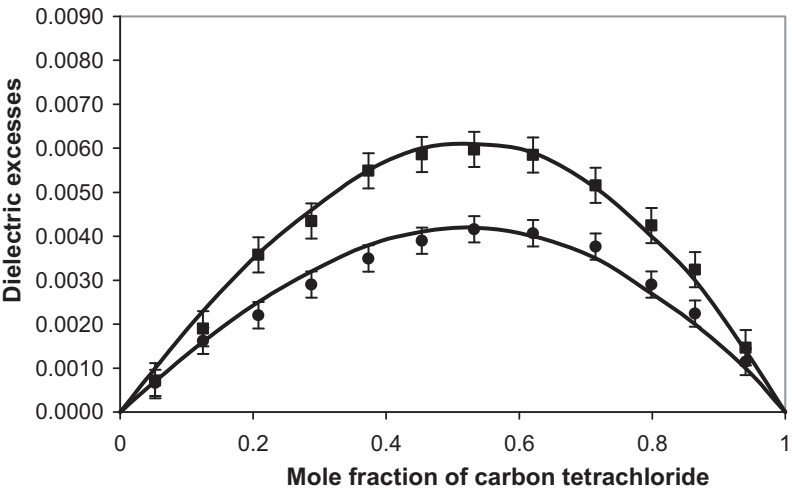

Figure 8. Dielectric excesses versus mole fraction $X$ for $\left[\mathrm{XCCl}_{4}+(1-X) p-\left(\mathrm{CH}_{3}\right)_{2} \mathrm{C}_{6} \mathrm{H}_{4}\right] . \varepsilon^{E}(\mathbf{\square}), n_{D}^{2^{E}}(\mathbf{O})$. The smoothed curves were calculated from the model considering a $\mathrm{CCl}_{4}$ : $p-\left(\mathrm{CH}_{3}\right)_{2} \mathrm{C}_{6} \mathrm{H}_{4}$ complex with the parameters given in Table 5 . Errors $\varepsilon^{E}: 4 \times 10^{-4} ; n_{D}^{2^{E}}: 3 \times 10^{-4}$.

The number of species in the solution is calculated using the equilibrium constants of the complexes that are given by the following relations:

$$
\begin{gathered}
K_{A B}=\frac{N_{A B}}{N_{A} N_{B}}=\frac{K_{A B}^{X}}{N} \\
K_{A B}^{X}=\frac{X_{A B}}{X_{A} X_{B}} \\
K_{A 2 B}=\frac{N_{A 2 B}}{N_{A B} N_{B}}=\frac{K_{A 2 B}^{X}}{N} \\
K_{A 2 B}^{X}=\frac{X_{A 2 B}}{X_{A B} X_{B}}
\end{gathered}
$$

To perform the theoretical curve of this mixture over $10^{6}$ random values for $K_{A B}^{X}, K_{A 2 B}^{X}, \alpha_{A 2 B}^{e}$, and $\alpha_{A B}^{e}$ were generated. Whenever the above parameters fit the dielectric excess at high frequency, random values for $\mu_{A B}$ and $\mu_{A 2 B}$ are generated until the dielectric excess at low frequency is fitted or a maximum of $10^{3}$ values generated are reached. When this step is completed the process returns to the starting point and start the fit again. For this mixture five total fits were made and in Table 6 the mean values and the corresponding errors are shown.

The values of $N_{A}, N_{B}, N_{A B}$, and $N_{A 2 B}$ are obtained with an iterative method by solving the set of equations:

$$
\begin{gathered}
N_{A}=N_{A}^{0}-N_{A B}-N_{A 2 B} \\
N_{B}=N_{B}^{0}-N_{A B}-2 N_{A 2 B}
\end{gathered}
$$


Table 6. Equilibrium constants, electronic polarizabilities, and dipole moments for the complexes $\mathrm{CCl}_{4}: \mathrm{C}_{6} \mathrm{H}_{6}$ and $\mathrm{CCl}_{4}: 2 \mathrm{C}_{6} \mathrm{H}_{6}$.

\begin{tabular}{|c|c|c|c|c|c|c|}
\hline Complex & $K_{A B}^{x}$ & $K_{A 2 B}^{X}$ & $\alpha_{A B}^{e} \times 10^{23}(\mathrm{ml})$ & $\alpha_{A 2 B}^{e} \times 10^{23}(\mathrm{ml})$ & $\mu_{A B}$ (Debye) & $\mu_{A 2 B}$ (Debye) \\
\hline $\mathrm{CCl}_{4}: \mathrm{C}_{6} \mathrm{H}_{6}$ & $0.19 \pm 0.02$ & & $2.134 \pm 0.004$ & & $0.433 \pm 0.006$ & \\
\hline $\mathrm{CCl}_{4}: 2 \mathrm{C}_{6} \mathrm{H}_{6}$ & & $0.15 \pm 0.05$ & & $3.172 \pm 0.007$ & & $0.52 \pm 0.05$ \\
\hline
\end{tabular}

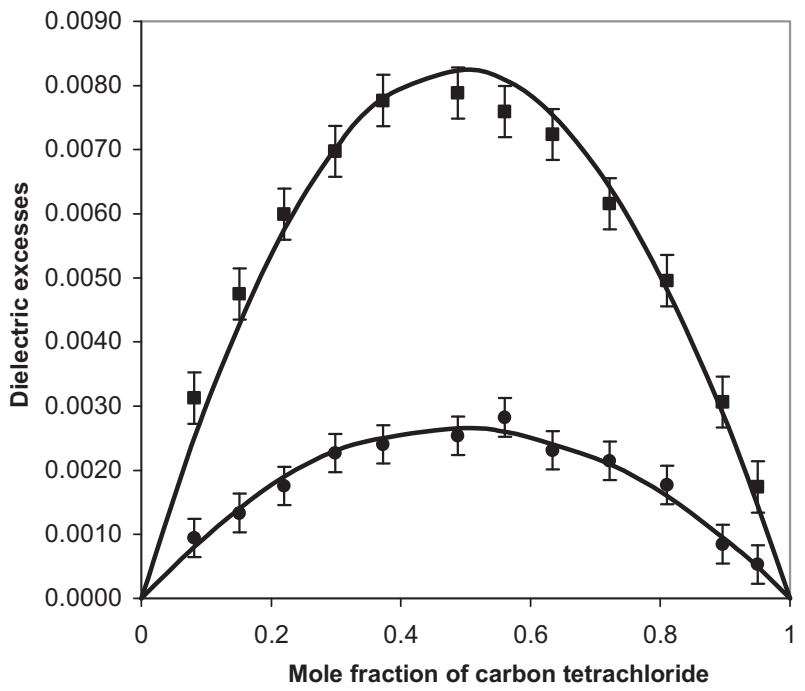

Figure 9. Dielectric excesses versus mole fraction $X$ for $\left[\mathrm{XCCl}_{4}+(1-X) \mathrm{C}_{6} \mathrm{H}_{6}\right] . \varepsilon^{E}(\mathbf{\square}), n_{D}^{2^{E}}(\bullet)$. The smoothed curves were calculated from the model with the parameters given in Table 6. Line: data fit with the model considering the $\mathrm{CCl}_{4}: \mathrm{C}_{6} \mathrm{H}_{6}$ complex. Errors $\varepsilon^{E}: 4 \times 10^{-4} ; n_{D}^{2^{E}}: 3 \times 10^{-4}$.

$$
\begin{gathered}
N=N_{A}^{0}+N_{B}^{0}-N_{A B}-2 N_{A 2 B} \\
N_{A B}=\frac{K_{A B}^{X} N_{A} N_{B}}{N} \\
N_{A 2 B}=\frac{K_{A 2 B}^{X} N_{A B} N_{B}}{N}=\frac{K_{A 2 B}^{X} K_{A B}^{X} N_{A} N_{B}}{N^{2}}
\end{gathered}
$$

where the initial values of $N_{A B}$ and $N_{A 2 B}$ are zero.

Figures 9 and 10 show the calculated curves for both dielectric excesses using the values given in Table 6. The experimental results were not fitted within the experimental error when only the $\mathrm{CCl}_{4}: \mathrm{C}_{6} \mathrm{H}_{6}$ complex is considered, however when the $\mathrm{CCl}_{4}: \mathrm{C}_{6} \mathrm{H}_{6}$ and $\mathrm{CCl}_{4}: 2 \mathrm{C}_{6} \mathrm{H}_{6}$ complexes are considered all the experimental points are fitted according to the model. The chi-square value is 8.37 when only the complex $\mathrm{CCl}_{4}: \mathrm{C}_{6} \mathrm{H}_{6}$ is considered and 6.73 when the $\mathrm{CCl}_{4}$ : $\mathrm{C}_{6} \mathrm{H}_{6}$ and $\mathrm{CCl}_{4}: 2 \mathrm{C}_{6} \mathrm{H}_{6}$ complexes are considered. The expected maximum values are respectively 16.919 and 12.592 for 9 and 6 degrees of freedom. Therefore the hypothesis with $\alpha=0.05$ is not discarded. There is no clear

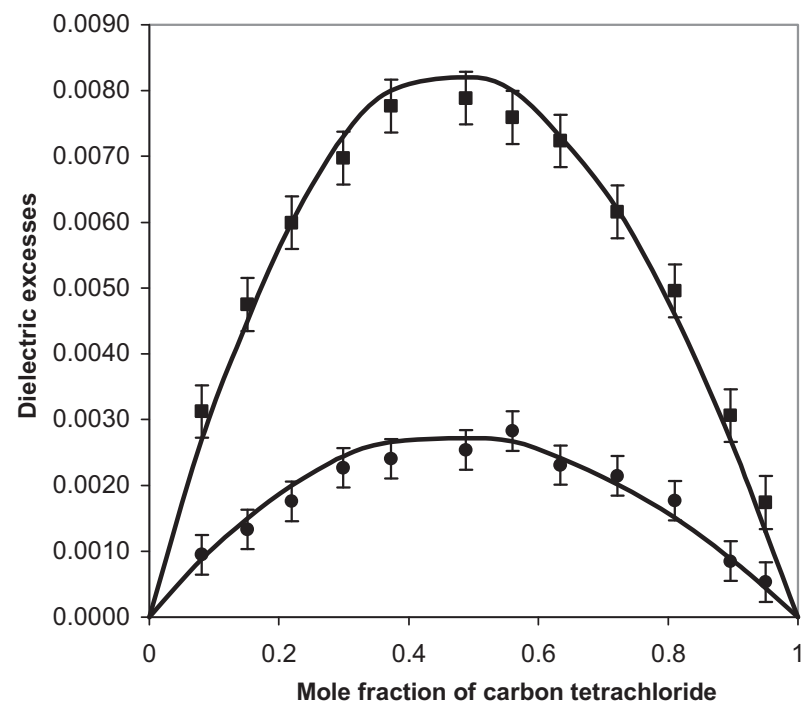

Figure 10. Dielectric excesses versus mole fraction $X$ for $\left[X_{C C l}+(1-X) C_{6} H_{6}\right] \cdot \varepsilon^{E}(\mathbf{\square}), n_{D}^{2^{E}}(\bullet)$. The smoothed curves were calculated from the model with the parameters given in Table 6 . Lines: data fit with the model considering the $\mathrm{CCl}_{4}: \mathrm{C}_{6} \mathrm{H}_{6}$ and $\mathrm{CCl}_{4}: 2 \mathrm{C}_{6} \mathrm{H}_{6}$ complexes. Errors $\varepsilon^{E}: 4 \times 10^{-4} ; n_{D}^{2^{E}}: 3 \times 10^{-4}$.

differences between the two values to ascertain the existence of the two complexes, but now the theoretical curve passes through all points, within the experimental value. This leads to think that the two complexes could exist and this should be verified through other methods.

It should also be mentioned that the relative errors in the parameters when the $\mathrm{CCl}_{4}: \mathrm{C}_{6} \mathrm{H}_{6}$ and $\mathrm{CCl}_{4}: 2 \mathrm{C}_{6} \mathrm{H}_{6}$ complexes are considered are all larger than in the case wherein the existence of a $\mathrm{CCl}_{4}: \mathrm{C}_{6} \mathrm{H}_{6}$ complex is considered to exist. This is so because there are several relative minima close to the absolute minimum when the best values of the parameters are generated randomly.

\section{CONCLUSIONS}

High precision permittivity values measured in this work made it possible to calculate dielectric excesses with a model indicating that $\mathrm{CCl}_{4}$ forms intermolecular complexes with benzene $\left(\mathrm{C}_{6} \mathrm{H}_{6}\right)$, toluene $\left(\mathrm{C}_{6} \mathrm{H}_{5} \mathrm{CH}_{3}\right)$ and p-xylene $\left(p-\left(\mathrm{CH}_{3}\right)_{2} \mathrm{C}_{6} \mathrm{H}_{4}\right)$.

This is achieved by using a model based on the additivity of the electrical susceptibilities of the species present in a solution that allows to calculate the dielectric excesses of a homogeneous mixture at different frequencies and in the 
whole range of concentrations. The excesses calculated in this work agree with the experimental values only when complex formations are considered in the mixtures. In particular, in the $\mathrm{CCl}_{4}+\mathrm{C}_{6} \mathrm{H}_{6}$ system the behavior of the dielectric excess at low frequency can only be explained if the $\mathrm{CCl}_{4}: \mathrm{C}_{6} \mathrm{H}_{6}$ and $\mathrm{CCl}_{4}$ : $2 \mathrm{C}_{6} \mathrm{H}_{6}$ complexes are considered to be present in the mixture. The most important and valuable characteristic of this treatment is that the method of generates easily random values of the various unknown parameters needed in the model to predict the dielectric excess of a mixture, can fit the experimental data. When only the 1:1 complexes in each mixture are considered, the randomly generated parameters that best fit the experimental data are in reasonable agreement with those of the literature. Therefore when other complexes are present this method allows to obtain a theoretical curve that has a good fit with the experimental results, confirming the need to consider the existence of interaction products, other than those of a 1:1 relation when systems of this kind are considered.

\section{ACKNOWLEDGMENTS}

We are greatly indebted to Dr. Máximo Barón of the Universidad de Belgrano for detailed and helpful discussions.

\section{REFERENCES}

[1] Buep AH, Barón M. Dielectric properties of binary systems. 7. Carbon tetrachloride with benzene, with toluene, and with p-xylene at 298.15 and 308.15 K. J Phys Chem. 1988;92(3): 840-43. doi:10.1021/j100314a049

[2] Buep AH, Rebollo Paz MB, Tourón JL. Dielectric properties of binary systems 9. Excess permittivities as the sum of several possible contributions. J Mol Liquids. 1990;45(3-4):237-52. doi:10.1016/0167-7322(90)80033-G

[3] Buep AH. Dielectric properties of binary systems 10. Ideal dielectric behavior and excess dielectric properties. J Mol Liquids. 1992;51(3-4):279-306. doi:10.1016/0167-7322(92) 80089-Z

[4] Buep AH, Rebollo Paz MB, Barón M. Influence of molecular anisotropies in the excess dielectric properties of binary liquid systems. J Mol Liquids. 1993;56:333-47. doi:10.1016/01677322(93)80037-V

[5] Boerio-Goates J, Goates SR, Ott JB, Goates JR. Enthalpies of formation of molecular addition compounds in tetrachloromethane + p-xylene, + toluene, and + benzene from (solid + liquid) phase equilibria. J Chem Thermodynamics. 1985;17 (7):665-70. doi:10.1016/0021-9614(85)90120-X

[6] Goates JR, Sullivan RJ, Ott JB. Heats of mixing in the system carbon tetrachloride-cyclohexane-benzene. J Phys Chem. 1959;63(4):589-94. doi:10.1021/j150574a034

[7] Youngs IJ, Stevens GC, Vaughan AS. Trends in dielectrics research: an international review from 1980 to 2004. J Phys D: Appl Phys. 2006;39(7):1267-76. doi:10.1088/0022-3727/39/7/S01

[8] Redlich 0, Kister AT. On the thermodynamics of solutions. IV. The determination of liquid-vapor equilibria by measuring the total pressure. J Am Chem Soc. 1949;71(2):505-7. doi:10.1021/ ja01170a035

[9] Barón M. Vapor-phase dipole moment values from solution measurements. J Phys Chem. 1985;89(22):4873-5.

[10] Kiyohara 0, Benson GC. Excess volumes of binary mixtures of tetrachloromethane with some aromatic liquids at $298.15 \mathrm{~K}$. J
Chem Thermodynamics. 1977;9(7):691-5. doi:10.1016/00219614(77)90095-7

[11] Riddick JA, Bunger WB. Techniques of chemistry, organic solvents: physical properties and methods of purification. 3rd ed., New York: Wiley-Interscience; 1970.

[12] Castex TA, de Vivar PD, Paz MBR, Buep AH. A new heterodynebeat circuit for the determination of static permittivity. Rev Sci Instruments. 199566(4):3067. doi:10.1063/1.1145530

[13] Knobler CM, Perez P, Block TE. Refractive index and dielectric constant of mixtures of carbon tetrachloride with benzene, p-xylene, and mesitylene. J Chem Eng Data. 1971;16(3):333-5. doi:10.1021/je60050a035

[14] Barón M, Calatroni J, Febrer M, Vara CD, de Rasemberg PA, Molina Nelson E. An instrument for the determination of dielectric constants in liquids. Acta Científica. 1968;1(4):43.

[15] Reis JCR, Iglesias TP, Douhéret G, Davis MI. The permittivity of thermodynamically ideal liquid mixtures and the excess relative permittivity of binary dielectrics. Phys Chem Chem Phys. 2009;11(20):3977-86. doi:10.1039/b820613a

[16] Buep AH. Dielectric properties of liquid systems: the ideal complex permittivity in liquid mixtures. Turk J Phys. 2009;33:243-7. doi:10.3906/fiz-0905-1

[17] Rosseinsky DR, Kellawi H. A statistical assessment of association constants. J Chem Soc (A), Inorg Phys Theor. 1969:1207-1211. doi:10.1039/j19690001207

[18] Ott JB, Goates JR, Budge AH. Solid-liquid phase equilibria and solid compound formation in mixtures of aromatic compounds with carbon tetrachloride. J Phys Chem. 1962;66(8):1387-90. doi:10.1021/j100814a004

[19] Rebollo Paz MB, Buep AH, Barón M. Dielectric properties of binary systems 8. Improved model for alcohol/non polar systems. J Mol Liquids. 1988;38(3-4):225-32. doi:10.1016/ 0167-7322(88)80020-5

[20] Onsager L. Electric moments of molecules in liquids. Chem Soc. 1936;58(8):1486-93. doi:10.1021/ja01299a050

[21] McGlashan ML, Stubley D, Watts H. Enthalpies of mixing and complex formation of carbon tetrachloride with benzene, toluene, p-xylene, and mesitylene. J Chem Soc (A), Inorg Phys Theor. 1969:673-8. doi:10.1039/j19690000673

\section{COMPETING INTERESTS}

The author declares no competing interests.

\section{PUBLISHING NOTES}

(C) 2015 Adrián H. Buep. This work has been published open access under Creative Commons Attribution License CC BY 4.0, which permits unrestricted use, distribution, and reproduction in any medium, provided the original work is properly cited. Conditions, terms of use and publishing policy can be found at www.scienceopen.com.

Please note that this article may not have been peer reviewed yet and is under continuous post-publication peer review. For the current reviewing status please click here or scan the QR code on the right.

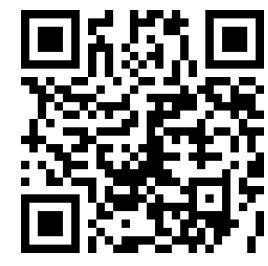

\section{scienceOPEN.com

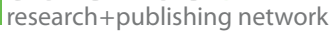

